\title{
El impacto de las nuevas tecnologías en la estética fotográfica. Tipologías en la obra de Pedro Meyer
}

\section{The Impact of New Technologies in Photographic Aesthetics. Typologies in the Work of Pedro Meyer}

Artículo recibido el 2 de febrero de 2020; devuelto para revisión el 9 de septiembre de 2020; aprobado el 20 de noviembre de 2020; https://doi.org/IO.2220I/iie.I8703062e.202I.119.2754

Nekane Parejo Universidad de Málaga, Facultad de Ciencias de la Comunicación, Departamento de Comunicación Audiovisual, nekane@uma.es, https://orcid.org/oooo-0003-3O2I-I223

Líneas de investigación Historia de la fotografía; relación fotografía-cine; imágenes artísticas.

Lines of research History of photography; relation between photography and cinema; artistic images.

Publicación más relevante "La fotógrafa Denise Bellon: surrealismo, documentalismo y fotografía humanista", Liño. Revista Anual de Historia del Arte, núm. 23 (2017): I39-I46, https://doi.org/IO.I78II/li.23.20I7.139-I46

Agustín Gómez Gómez Universidad de Málaga, Facultad de Ciencias de la Comunicación, Departamento de Comunicación Audiovisual, aggomez@uma.es, https://orcid.org/oooo-0002-1736-0630

Líneas de investigación Relación cine-arte; el cine del yo; el cine rural y el documental.

Lines of research The relation between cinema and art; the cinema of the self; rural cinema and the documentary.

Publicación más relevante "Autorretrato, retrato de familia y autoficción en Días de agosto (2005) de Marc Recha”, Revista de Comunicación, núm. I9 (marzo, 2020): Io9I23, https://doi.orgIo.2644I/RCI9.I-2020-A7

Resumen Pedro Meyer es un pionero y un paradigma del tránsito de la fotografía analógica a la digital. El propósito de esta investigación es ahondar en su obra y métodos de trabajo para establecer y definir las tipologías de su trayectoria. Para lograrlo se seguirá una metodología de análisis de contenido que contará con una muestra que incluye las publicaciones: Fotografio para recordar (I991), Verdades y ficciones: un 
viaje de la fotografía documental a la digital (1995) y su versión CD ROM, The Real and the True y Herejias (2008). A partir de su estudio se intentará revelar cómo el paso de las imágenes en papel a formatos digitales no resulta un impedimento para que permanezcan ciertas estéticas inherentes a las imágenes.

Palabras clave Fotografía digital; fotografía analógica; manipulación fotográfica; Pedro Meyer; estética fotográfica.

Abstract Pedro Meyer is a pioneer and a paradigm of the transition from ana$\log$ to digital photography. The purpose of this research is to deepen his work and work methods so as to establish and define the typologies of his career. To achieve this, a content analysis methodology will be followed in a qualitative version that will address a sample including: I photograph to remember (1991), Truths and Fictions: a Journey from Documentary Photography to Digital Photography (1995) and its CD ROM version, The Real and the True, and Heresies (2008). From the study of the exhibition an attempt will be made to reveal how the conversion of images from paper to digital formats is not an impediment to maintaining certain aesthetics inherent in his work.

Keywords Digital photography; analogic photography; photo manipulation; Pedro Meyer; photographic aesthetics. 
DOI: https://doi.org/10.22201/iie.18703062e.2021.119.2754

\author{
NEKANE PAREJO Y AGUSTÍN GÓMEZ GÓMEZ \\ UNIVERSIDAD DE MÁLAGA
}

\title{
El impacto de las nuevas tecnologías en la estética fotográfica Tipologías en la obra de Pedro Meyer
}

Sobre la obra de Pedro Meyer. Introducción, objetivos y metodología

U n recorrido por la obra del fotógrafo mexicano (nacido en España) Pedro Meyer evidencia que estamos ante una referencia obligada en fotografía contemporánea. Una primera observación de orden cuantitativo nos lleva a valorar su elevada producción. En 2008 el fotógrafo se refería a la problemática que le supuso realizar una selección en el año 2002 de cara al ofrecimiento del director del Centro de la Imagen en Ciudad de México, Alejandro Castellanos, para hacer una retrospectiva de sus cinco últimas décadas (lo que se materializaría en Herejías, de la que trataremos más adelante). En relación a esta propuesta aportó los siguientes datos:

Había en mis archivos 80 mil fotografías de un tema concreto, Estados Unidos; de otro, los petroleros, I8 mil; algún otro más con 20 mil... y así sucesivamente hasta llegar a más de 300 mil imágenes. Resultaba obvio que "elegir" únicamente seis fotos de cada tema terminaba siendo una propuesta no sólo banal, sino inaceptable. ${ }^{1}$

I. Pedro Meyer, "Tras las bambalinas y una serie de agradecimientos", en Herejías, ed. Pedro Meyer (Barcelona: Lunwerg, 2008), 333. 


\section{DOI: https://doi.org/10.22201/iie.18703062e.2021.119.2754}

Desde esta perspectiva somos conscientes de las dificultades que entraña el propósito de nuestra investigación, la cual profundiza en las imágenes de este autor y sus modos de trabajo, pero también pretende establecer las tipologías que convergen en su trayectoria, así como apreciar el impacto que las nuevas tecnologías han producido en su obra.

Nuestro trabajo parte de un artículo anterior titulado "De la fotografía documental al documento digital". ${ }^{2}$ En él, con base en las reflexiones de Meyer sobre su obra, argumentábamos que este fotógrafo consideraba que sus imágenes no debían depender del azar o del encuentro del instante apropiado. Además, considerábamos que el acto fotográfico se situaba en las antípodas de fotógrafos como Henri Cartier-Bresson, para quien obtener el "momento decisivo" se constituía en el fundamento de sus instantáneas, pero a la par constatábamos que Meyer catalogaba sus tomas de documentales. Esto nos ha llevado a repensar, en este texto, el concepto de formato en su quehacer ya que a lo largo de su carrera hallamos tomas analógicas y digitales que evidencian un instante decisivo mediante un único disparo de cámara.

De forma genérica, Meyer divide su obra en dos fases, que se corresponden con las diferentes herramientas empleadas: A.C. (antes de las computadoras) y D.C. (después de las computadoras). Estas etapas incluyen fotografías analógicas y digitales sin retoque, fotografías analógicas en soporte digital, la combinación y manipulación de analógicas y digitales, y estas últimas modificadas con programas de computadora. Ambos periodos confluyen en el proyecto Herejías, en el que todas las tipologías tienen cabida.

El método que se empleará para abordar la producción de Meyer es el análisis de contenido en su versión cualitativa del conjunto de fotografías que resultó de la revisión de la obra completa, y que conformó Herejias (por el autor y los comisarios). Desde ahí, la muestra acotada se compone del primer CD ROM del mundo con imágenes y sonido, Fotografio para recordar (1991), ${ }^{3}$ el libro Verdades y ficciones: un viaje de la fotografía documental a la digital $(1995)^{4}$ y su

2. Nekane Parejo, "De la fotografía documental al documento digital”, Revista Zer I3, núm. 25 (diciembre de 2008): 179-196.

3. Esta obra se encuentra en el siguiente enlace que pertenece a la página web del fotógrafo: https://pedromeyer.com/es/apendice-fotografio-para-recordar/

4. Pedro Meyer, Verdades y ficciones: un viaje de la fotografía documental a la digital (Ciudad de México: Casa de las Imágenes, I995). 
version de CD ROM, The Real and the Trues y Herejias (2008). ${ }^{6}$ En torno a estas publicaciones se establecen dos categorías principales: lo digital como soporte y las tipologías de la obra de Meyer. En esta última se estudiarán, a su vez, tres subcategorías de elaboración propia: el instante decisivo mediante disparo analógico y digital, el instante decisivo creado digitalmente, y la imagen discordante o la ficción digital detectable.

Nuestro propósito es determinar que estamos, como el mismo fotógrafo señala, ante "una obra en proceso". 7 Un proceso en el que el tránsito de las imágenes en papel a formatos digitales no es óbice para que mantenga la tradición fotográfica documental. Un recorrido que comienza a los 12 años $^{8}$ con una toma hoy extraviada y de la que el autor rememora el momento:

Recuerdo mi primera fotografía: un borreguito negro que había nacido de una borrega blanca. En 1947 caminaba por el valle de la Marquesa con mi primera cámara, una Brownie. Observé entonces una oveja que estaba pariendo; no salía de mi asombro al ver que esa oveja blanca estaba dando a luz un borreguito negro. ${ }^{9}$

En cualquier caso, y aunque se trata de una fotografía de la infancia y de una toma de contacto con el medio, estamos ante una imagen significativa en su ámbito familiar, ya que contribuyó a dibujar su perfil de oveja negra. ${ }^{10}$ No en vano, cuando a los 38 años comunicó que iba a dejar la empresa que dirigía para dedicarse profesionalmente a la fotografía, sus intenciones no fueron bien acogidas por su padre. ${ }^{\text {II }}$

El trabajo de Meyer, como afirma Cecilia Vidal: "es ante todo el resultado de una inmensa curiosidad, de una inquietud por indagar en las nuevas

5. Pedro Meyer, The Real and the True. The Digital Photography of Pedro Meyer (Indianápolis: New Riders Publishing, 2005).

6. Meyer, Herejías, http://www.pedromeyer.com/book/indexsp.html

7. Jorge Salgado, "Meyer una obra en proceso", https://Ilibrary.co/document/rz337dmzpedro-meyer-un-poeta-de-la-luz.html (consultado el 25 de marzo de 2019).

8. Pedro Meyer se hace eco de cómo, con anterioridad, a los nueve años sentía una fuerte atracción por la magia del laboratorio fotográfico.

9. Benjamín Mayer, "Negro. Oveja. Mago", en Herejías, 27.

Io. Benjamín Mayer reflexiona sobre esta fotografía a la que considera no sólo su primer retrato, sino su primer autorretrato. Mayer, "Negro. Oveja. Mago", 27-30.

II. Para más información sobre aspectos biográficos véase: Mayer, "Negro. Oveja. Mago", 19-30. 


\section{DOI: https://doi.org/10.22201/iie.18703062e.2021.119.2754}

posibilidades que la tecnología trae cada día". ${ }^{12}$ De hecho, estamos ante un pionero de la fotografía digital que en 1979 comenzó a tratar las imágenes, aunque con más dedicación a partir de que adquiere la primera Apple que se vendió en México en 1983, en concreto, una Macintosh IIfx de 40 Mhz. En este sentido, Christian Caujolle ratifica que: "antes que nadie percibió, primero intuitivamente y luego totalmente consciente los límites de la fotografía y las mutaciones a las que conducían los nuevos avances tecnológicos". ${ }^{13}$ Él mismo recuerda en una entrevista de Jorge Salgado sus comienzos digitales y cómo sus nuevas imágenes no fueron bien recibidas, hasta el punto que muchos las consideraron banales y se preguntaban los motivos por los que invertía su tiempo y dinero en ellas. Sin embargo, afirma: "me di cuenta a los diez minutos de estar haciendo las imágenes que esto era 20 veces más adecuado para el futuro en comparación con la fotografía que estábamos haciendo". ${ }^{14} \mathrm{Y}$ con esta convicción comienza su viaje desde los negativos de su laboratorio ${ }^{\text {Is }}$ hasta los programas de retoque fotográfico.

\section{Lo digital como soporte}

El proceso evolutivo de la tecnología analógica a la digital fue lento y marcado por un necesario aprendizaje de esta novedosa herramienta. Es preciso tener presente que las transformaciones que se producen están relacionadas no sólo con el hecho de elaborar las tomas, sino también con la forma en que éstas se ponen en circulación. Por tanto, nos encontramos ante un proceso paulatino que parte de unas fotografías vinculadas al ámbito personal y que Meyer quiere que lleguen a una colectividad de sujetos fuera de su alcance más próximo. Ya en la primavera de 1993 este autor se refería al cambio de siglo como un punto de inflexión en el que soportes en ese momento desconocidos compartirían espacio con los tradicionales y afirmaba: "algunas de esas alternativas se

I2. Cecilia Vidal, "Pedro Meyer. En busca de lo que vendrá. El fotógrafo mexicano inaugura en Montevideo la muestra retrospectiva de su obra", Revista Dixit, núm. 23 (julio-diciembre de 2015): 64 .

13. Christian Caujolle, "Presentación", en Herejias, i5.

I4. Salgado, "Pionero de la fotografía", http://www.revista.unam.mx/vol.5/numg/ent2/ent22.htm (consultado el 25 de marzo de 2019).

15. Recordemos que las primeras tiras de contactos las lleva a cabo a los I3 años gracias a que un amigo de su padre, Gerhard Herzog, le regaló el equipo. 
encuentran en los discos CD ROM; discos de láser; redes de fibra óptica; transmisión vía satélite; transmisión por cable; tarjetas de memoria ultrarrápida” ${ }^{16}$ Precisamente en esta línea animaba tres años después a los fotógrafos a distribuir su trabajo en CD ROM o en Internet. ${ }^{17}$

En este punto es preciso señalar que en I99I publicó el primer CD ROM en el mundo con sonido ${ }^{18} \mathrm{e}$ imagen continuos, Fotografio para recordar. ${ }^{19}$ Hasta ese momento este material estaba conformado por una caja de impresiones que el fotógrafo mostraba a sus allegados. El hecho de transferirlas a este novedoso sistema supuso un punto de inflexión en su trayectoria, que a partir de entonces quedará definitivamente marcada por los avances de la tecnología digital. En el caso que nos ocupa, a finales de los años 90 tuvo que trasladarse a Shockwave debido a que el formato Macro Media Director Player se había quedado desfasado y resultaba ilegible.

Fotografio para recordar es, por tanto, un trabajo que nos permite acceder a casi un centenar de fotografías en blanco y negro que recorren la vida de los padres de Meyer desde su noviazgo hasta los últimos momentos de la existencia de ambos, víctimas del cáncer. Nos encontramos ante un producto propio de la narrativa digital que, como define Richard Héctor Jones, "normalmente se presenta como cortos relatos multimedia, con mucho sentimiento y a menudo están hechos con fotos, texto y música, y de aproximadamente dos minutos de duración” ${ }^{20} \mathrm{Si}$ exceptuamos la duración, el que nos ocupa es de 35 minutos, la pieza cumple con los rasgos comunes expuestos. De hecho, se trata de una producción austera en la que se combinan fotos, texto y la emotiva voz de Meyer. En este sentido, Jonathan Green desarrolla el concepto de narrativa en su texto introductorio y matiza que "no es un producto digital, sino más bien una expresión digital” en la que confluyen la fotografía y la

I6. Pedro Meyer, "La revolución digital”, Luna Córnea, núm. 2 (primavera de 1993): 4I, https://www.circuloa.com/luna-cornea-2-nuevas-tecnologias/ (consultado el 2 de enero 2020).

17. Alex Barnett, "Pedro Meyer. Fotógrafo digital", https://n9.cl/xtavq (consultado el 23 de marzo de 2018).

I8. Será su hijo Manuel Rocha quien se encargará de componer la música.

19. Posteriormente en 2006 se reactualizó y se creó la posibilidad de que pudiera bajarse en diversos formatos, entre ellos a un iPod. En la actualidad está disponible de forma gratuita en https://pedromeyer.com/es/apendice-fotografio-para-recordar/

20. Richard Héctor Jones, "Relatando historias", http://zonezero.com/magazine/articles/ jones/indexsp.html (consultado el 4 de febrero de 20I9). 


\section{DOI: https://doi.org/10.22201/iie.18703062e.2021.119.2754}

56 NEKANE PAREJO Y AGUSTÍN GÓMEZ GÓMEZ

memoria. En concreto, señala que se trata de una narración: "construida con ayuda de la fotografía" ${ }^{21}$

Una producción que entronca con el género del álbum familiar, pero con altas dosis de innovación y coraje por parte del fotógrafo. De hecho, de acuerdo con Serge Tisseron: "Las fotografías que revelan signos de una enfermedad en uno de los miembros de la familia son intencionadamente separadas en vida del enfermo. De lo contrario, una vez fallecido, esas fotografías pueden volver a ser reagrupadas." ${ }^{22}$ Aquí la naturalidad con la que se desarrolla el acto fotográfico es subrayada por el autor y por sus padres, lo que no es obstáculo para que el público lo acoja con cierta extrańeza: "A menudo me han preguntado cómo pude fotografiar a mis padres en las situaciones en que lo hice. Siempre fotografié a mi familia: la cámara era entre nosotros un instrumento omnipresente, prácticamente transparente a nuestros ojos." ${ }^{23}$

En esta obra destaca la ausencia de manipulación digital, pero sobre todo la austeridad con la que se muestran estas tomas en clave documental y que el fotógrafo presenta deliberadamente como si se tratara de pasar diapositivas. ${ }^{24}$ En este sentido, Ińigo Sarriugarte manifiesta que: "El autor optó más por la narración y la coherencia artística que por el desarrollo excesivo de la tecnología, mostrando de esta manera si cabe aún más el valor humano del proyecto." ${ }^{25}$ Un proyecto que parece inspirado en las palabras de Proust cuando se refería a que se reconoce mejor a nuestros allegados en una imagen fotográfica que en nuestros recuerdos. ${ }^{26}$

De hecho, el título no responde a la casualidad, Meyer ha expresado en diversas ocasiones que registrar ciertos momentos le ha resultado de utilidad para suplir la falta de memoria. Además, esta publicación le permitiría afrontar

2I. Jonathan Green, "El arte del relato: fotografío para recordar", http://v2.zonezero. $\mathrm{com} /$ index.php?option=com_content\&view=article\&id=I352\%3Athe-art-of-storytelling-pedro-meyers-i-photograph-to-remember\&catid $=5 \% 3$ Aarticles\&lang=es (consultado el $5 \mathrm{de}$ septiembre de 2020).

22. Serge Tisseron, El misterio de la cámara lúcida. Fotografía e inconsciente (Salamanca: Ediciones Universidad de Salamanca, 2000), I35-I36.

23. Mayer, "Negro. Oveja. Mago", 24.

24. Es necesario recordar que se trata de un formato que habían trabajado otros fotógrafos como Raymond Depardon en Les années Declick (1984). La novedad estriba en el formato CD ROM.

25. Iñigo Sarriugarte, "Pedro Meyer y la propuesta Fotografio para recordar: una mirada al retrato familiar", en Cuartas Jornadas. Imagen, cultura y tecnología, eds. María Pilar Amador, Jesús Robledano y María del Rosario Ruiz Franco (Madrid: Editorial Archiviana, 2006), 215. 26. Tisseron, El misterio de la cámara lúcida, $\mathrm{I} 23$. 
el duelo: "no terminaría de enfrentar apropiadamente la muerte de mis padres hasta haber terminado de imprimir las fotos que había tomado". ${ }^{27}$

Con el mismo formato CD ROM se publica Truths and Fictions (1993) que dos años después adquirirá formato libro como Verdades y ficciones: un viaje de la fotografía documental a la digital (1995). Paradójicamente este trabajo es coetáneo a Fotografío para recordar, pero Bob Stein de la Voyager Company, al ver las imágenes de los padres de Meyer, priorizó este proyecto.

Verdades y ficciones cuenta con un recorrido peculiar. Se trata de una obra que surge desde un planteamiento analógico en cuanto al acto fotográfico se refiere, pero que se editará en digital para finalmente retornar a lo analógico en formato libro. Aun así, la publicación impresa también contó con Internet como poderosa arma de diseño, cuya ejecución corrió a cargo de Pedro Meyer y una diseñadora neoyorquina, Wendy Byrne, a la que no conoció en persona sino hasta el día de la presentación del libro y cuyas interacciones laborales fueron exclusivamente digitales. La misma suerte tuvo la edición digital coordinada entre el autor residente en esas fechas en Los Ángeles y la editorial en Nueva York. Si bien esta forma de trabajo no supuso obstáculo alguno, Meyer hace hincapié en otra cuestión relacionada:

con la distribución física que volvía inexistente a la obra por ser tan difícil de encontrarla en cualquier parte. En principio muy pocos lugares vendían CDROMS [...] Más adelante, cuando creció el interés se construyeron secciones enteras en las librerías [...] La competencia por el espacio en las repisas de los libreros se volvió feroz. ${ }^{28}$

En cualquier caso, Verdades y ficciones, la primera exhibición de imágenes digitales, es una confrontación en clave de road movie entre el México más atávico y los Estados Unidos de la etapa de Ronald Reagan. La abundancia y la escasez del norte y el sur respectivamente, se evidencian entre las discordancias de lo rural y lo urbano que vienen delimitadas por la frontera que separa a estos dos países. Pero, además, y de acuerdo con Inés Bortagaray, ${ }^{29}$ este trabajo no sólo muestra estas divergencias, sino que la combinación de posibles encuentros abarca otras posibilidades

27. Green, "El arte del relato".

28. Pedro Meyer, "algunos pensamientos de fondo".

29. Para mayor información al respecto consúltese http://www.henciclopedia.org.uy/autores/Bortagaray/Meyerz.htm 


\section{DOI: https://doi.org/10.22201/iie.18703062e.2021.119.2754}

58

NEKANE PAREJO Y AGUSTÍN GÓMEZ GÓMEZ

entre las que destacan aquellas vinculadas a la crítica social, en las que prevalece la fantasía o en las que una nueva frontera se establece entre lo real y lo ficticio.

En este sentido, nos encontramos con unas tomas en las que el pasado y el presente se fusionan y se retocan con la memoria como eje vertebrador. Además, el fotógrafo se:

adentra en la encrucijada de la manipulación armado con la retórica de la paradoja (fotos que parecen retocadas y no lo han sido; fotos que parecen reales y no lo son) y ofrece al espectador la eficacia de unas imágenes surgidas del cruce entre la perfecta técnica quirúrgica de la informática y el viejo espíritu de los fotomontadores..$^{30}$

El trabajo de Meyer, en cuanto a soporte digital, no se limita a la distribución mediante CD ROM de su obra. En 1995 crea el espacio digital ZoneZero (http:// zonezero.com/es/). ${ }^{31}$ En la actualidad esta galería digital y medio de intercambio entre autores de todo el mundo, se encuentra dividido en ZoneZero 2.0 y ZoneZero 3.0 que aglutinan tres etapas claramente diferenciadas. La primera, De lo analógico a lo digital, se corresponde con unos inicios que abogan por el campo de la reflexión en torno al tránsito tecnológico que se está produciendo. Además, en palabras de Enrique Soto, citando a Mark Harworth-Booth, "él pensó que dirigiendo una revista en línea permitiría, por un lado, ofrecer un puente entre la fotografía analógica y digital y, por otra parte, le permitiría mantenerse al día debido al constante flujo de innovaciones técnicas". ${ }^{32}$ Podemos decir que durante esta etapa se potencia un nuevo contexto, el digital, aunque predomine la fotografía analógica. La segunda, denominada Desde la pantalla de luz, abarca el periodo de 2010 a 2013, donde en artículos y las muestras de casi 400 galerías se recoge la evolución de la imagen digital desde aspectos como la producción, la distribución y el consumo.

30. Barnett, "Pedro Meyer. Fotógrafo digital".

3I. En sus inicios este portal de fotografía se dividía en dos espacios: "La Galería, para trabajos individuales, y El Portafolio, dedicado a muestras colectivas. A estas dos propuestas se suman editoriales, noticias y foros de discusión en torno a la fotografía”. Véase Nekane Parejo, "De la fotografía documental al documento digital", Revista Zer I3, núm. 25 (diciembre de 2008): I82.

32. Enrique Soto, "Pedro Meyer", Revista Elementos, Ciencia y Cultura, núm. 78 (abril-junio de 2010): 57, www.elementos.buap.mx (consultado el 29 de marzo de 2019). 
La tercera etapa ZoneZero 3.0 y la convergencia fotográfica aborda un recorrido en el que confluyen diversas disciplinas que de acuerdo con su director Alejandro Malo (2OI4) son: "un encuentro más amplio hacia el cual avanzamos quienes vamos desde la fotografía. Es a través de este encuentro donde coinciden medios, geografías, usos, prácticas sociales y demás". ${ }^{33}$ Se enfatiza la última versión de este espacio digital (inserto en la Fundación Pedro Meyer) en el que se comparten conocimientos e imagen mediante la difusión, el diálogo y la educación. Como afirma el autor en cuestión: "la clave de la fotografía de hoy no reside tanto en que todo el mundo tenga una cámara incorporada, sino en el crecimiento exponencial de su distribución casi instantánea”. ${ }^{34}$

La experiencia que había ido adquiriendo en la primera fase de ZoneZero le resultó útil para organizar Herejías, una muestra retrospectiva (la mencionábamos al inicio de este texto) que se celebró en octubre de 2008. Pero Herejías no fue una exposición al uso, ya que se pudo contemplar en 65 museos de forma simultánea y contó con 20 comisarios de diferentes países. Además, el proyecto incluyó una exposición y un comisariado propio para cada museo, a la par que una muestra en línea y un libro común para todos ellos. De esta forma, Meyer vuelve a revolucionar las fórmulas de exhibición y plantea utilizar el soporte digital como medio alternativo a las imágenes impresas en papel que se mostrarían en las diferentes sedes. Como si de salas cinematográficas se tratara, su producción contaría con un alcance sincrónico por parte de estos museos mediante una base de datos con acceso mundial. De este modo, no quedaría en el olvido parte de su obra, tal y como expone el fotógrafo: "al entrelazar la exposición en línea con la muestra física, se abrirían numerosas posibilidades. Ya que mientras un museo puede exponer obras impresas a grandes tamańos, la red es capaz de mostrar una cantidad mucho mayor de imágenes". ${ }^{35}$ Por tanto, Herejías parte de un planteamiento en el que se pretende dar cabida a la mayor parte de la obra de Meyer desde la cultura de la globalización, pero sin dejar de lado la idiosincrasia de lo local. Para terminar, es necesario mencionar su página web oficial, ${ }^{36}$ en la que, tras la presentación del fotógrafo en el link de inicio, se tiene acceso a su trayectoria profesional que incluye una rela-

33. Alejandro Malo, "ZoneZero 3.0 y la convergencia fotográfica”, https://alejandromalo. com/20I4/o5/26/convergencia-fotografica/ (consultado el 5 de septiembre de 2020).

34. Vidal, "Pedro Meyer. En busca de lo que vendrá", 67.

35. Pedro Meyer, "Tras las bambalinas y una serie de agradecimientos", en Herejías, 335.

36. Para la página web oficial de Pedro Meyer consúltese el siguiente enlace: www.pedromeyer.com 


\section{DOI: https://doi.org/10.22201/iie.18703062e.2021.119.2754}

60

NEKANE PAREJO Y AGUSTÍN GÓMEZ GÓMEZ

ción de exposiciones individuales y colectivas, un listado de los museos e instituciones en lo que cuenta con obra, certámenes en los que ha sido jurado, conferencias y talleres impartidos, intervenciones en televisión, premios y publicaciones. En otros links se desglosan sus proyectos más relevantes como son ZoneZero, Herejias, la Fundación y la presentación de su archivo. Además, incluye enlaces a las redes sociales Facebook e Instagram.

\section{Tipologias en la obra de Pedro Meyer}

Las tipologías que aquí se establecen están fundamentadas en la publicación Herejias. ${ }^{37}$ Los criterios de selección de ésta encuentran su justificación en dos razones. La primera, porque este proyecto aglutina la obra más representativa del autor (independientemente de que algunas imágenes hubieran sido publicadas con anterioridad), la segunda, porque en los pies de las fotografías, además del título, incluye información sobre el modo de producción o en su caso manipulación de la toma. Ya en 1993 el fotógrafo manifestaba: "ahora tendremos que dejar muy claro para todo aquel interesado, cuándo una fotografía es un documento testimonial y cuándo no lo es". ${ }^{38}$

\section{El instante decisivo con disparo analógico y digital}

Partimos del clásico planteamiento de Henri Cartier-Bresson, fotógrafo que acunó la expresión "instante decisivo": "Para mí la fotografía es el reconocimiento simultáneo, en una fracción de segundo, por una parte, del significado de un hecho, y, por otra, de una organización rigurosa de las formas percibidas visualmente que expresan ese hecho" ${ }^{39}$ Es el caso de Detrás de la Estación de St. Lazare (1932),$^{40}$ entre muchas tomas de su producción. Ahí, el autor fue capaz, en una fracción de segundo, de darse cuenta del significado del brinco de un hombre sobre un charco y, a la vez, conseguir encuadrar la toma en función de

37. En el siguiente enlace puede encontrarse este catálogo en formato electrónico descargable: http://v3.pedromeyer.com/es/proyectos/herejias

38. Meyer, "La revolución digital", 47.

39. Henri Cartier-Bresson, Fotografiar al natural (Barcelona: Gustavo Gili, 1984), 29.

40. Esta fotografía puede consultarse en, https://www.theimagen.com/tras-la-estacion-de-san-lazaro-el-momento-decisivo-de-cartier-bresson/ 
las formas entre las que destaca un cartel al fondo en el que otra persona, una bailarina, está realizando la misma acción de saltar.

En función de lo expuesto, esta categoría está compuesta por aquellas imágenes en las que Meyer, ya bien en formato analógico o en digital, ha captado con el disparador de su cámara el momento preciso. Basta recordar entre los instantes analógicos tomas como Paulus (196I), ${ }^{4 \mathrm{I}}$ donde apreciamos el nacimiento de un bebé; Miradas libres (1974), ${ }^{42}$ que muestra a unos niños escudriñando la parte delantera de una cámara en trípode, mientras el resto dirige sus ojos hacia el cielo; El exposimetro (1976), ${ }^{43}$ en la que dos hombres desnudos conversan con sus cámaras fotográficas al cuello, mientras un exposímetro cubre el miembro sexual del que se encuentra a la derecha; El balazo (1979), ${ }^{44}$ en la que coincide una figura humana en el agujero que un proyectil ha producido en un cristal en primer plano; Dirigentes (1979), ${ }^{45}$ una imagen que recuerda a Eric Salomon, donde se muestra a tres guerrilleros nicaragüenses sentados en sus respectivas sillas, en un momento distendido; o El Partenón (1996), ${ }^{46}$ en la cual se observa a dos perros en pleno encuentro sexual con el edificio homónimo tras ellos.

Destacamos aquí dos fotografías. La primera de 1962, cuyo título, Un momento decisivo, ${ }^{47}$ hace referencia al enunciado que aquí tratamos y lo muestra mediante el instante en el que un padre de familia sujeta a un niño mientras su madre le quita el calzoncillo para orinar. La segunda es Mi padre volando (1987)..48 Sobre ésta, Green (2008) afirma: "la expresiva y panorámica imagen del padre volando invita a la metáfora de la transición entre lo analógico y lo digital". ${ }^{49}$ Este mismo autor se hace eco de cómo Meyer en sus producciones digitales "transforma la tierra en aire mediante Photoshop", mientras ahí su progenitor se encuentra "de rodillas sobre una silla con sus brazos estirados no hacia el

4I. Esta obra parte de un negativo en formato 6 × 6 . La imagen y las características de la misma pueden consultarse en Meyer, Herejias, 5r. También en https://pedromeyer.com/en/ herejias/ (consultado el 3 de febrero de 2019).

42. Esta obra parte de un negativo en formato $6 \times 6$, Meyer, Herejías, I48.

43. Meyer, Herejías, 42 (a partir de un negativo de $35 \mathrm{~mm}$ ).

44. Meyer, Herejías, 67 (a partir de un negativo de $35 \mathrm{~mm}$ ).

45. Meyer, Herejías, IO2 (a partir de un negativo de $35 \mathrm{~mm}$ ).

46. Meyer, Herejías, 88-89 (a partir de un negativo de $35 \mathrm{~mm}$ ).

47. Meyer, Herejías, 53 (a partir de un negativo en formato $6 \times 6$ ).

48. Meyer, Herejías, 2I4-2I5 (a partir de un negativo de $35 \mathrm{~mm}$ ).

49. Green, "El arte del relato". 


\section{DOI: https://doi.org/10.22201/iie.18703062e.2021.119.2754}

62 NEKANE PAREJO Y AGUSTÍN GÓMEZ GÓMEZ

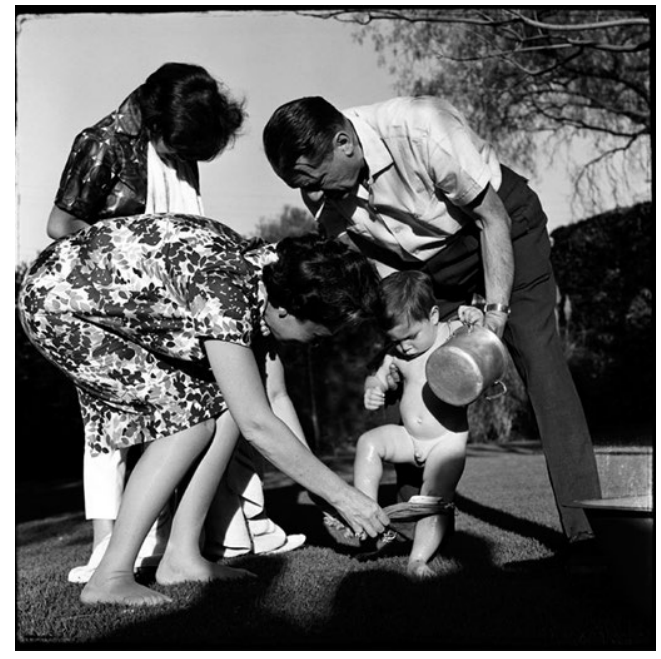

I. Pedro Meyer, Un momento decisivo, 1962, Ciudad de México, MXDIFEMXSSFF-FDOOOI3-OOI.

(C) Archivo Pedro Meyer.

cielo sino hacia el interior de la elegante y costosa sala de su casa, su gesto de vuelo está anclado en el dolor de la realidad"so (figs. I y 2).

Otras fotografías analógicas sobre las que debemos detenernos son aquellas realizadas en película de 35 milímetros que captan un momento decisivo, pero parecen estar manipuladas. Es el caso de dos imágenes de 1985: La libertad enterrada ${ }^{5 \mathrm{r}}$ y El diablo en Nueva York. ${ }^{52}$ En la primera se aprecia tras una alambrada un busto de la estatua de la libertad enterrado en la Ciudad de México, en la segunda, destaca un rostro que no parece real de un hombre en primer plano. Ambas delatan cómo, desde sus inicios, Meyer combina su interés por el registro puro, a la par que siembra en el espectador la incertidumbre sobre los mecanismos empleados para obtener la toma.

Como vemos con la fotografía analógica, algunas de sus imágenes parecen estar modificadas. En este sentido, resulta significativa la comparación entre dos fotografías. Se trata de Palmeras en la oficina (1987), ${ }^{53}$ en negativo de 35 milímetros, y El contador de historias (1991/1995), ${ }^{54}$ que parte de una transparencia en analógico modificada digitalmente. En ambas el fondo visual es el prota-

\footnotetext{
50. Green, "El arte del relato".

5I. Puede consultarse en Meyer, Herejías, 99.

52. Meyer, Herejías, 206-207.

53. Meyer, Herejias, 302.

54. Meyer, Herejías, 303.
} 


\section{DOI: https://doi.org/10.22201/iie.18703062e.2021.119.2754}

EL IMPACTO DE LAS NUEVAS TECNOLOGÍAS

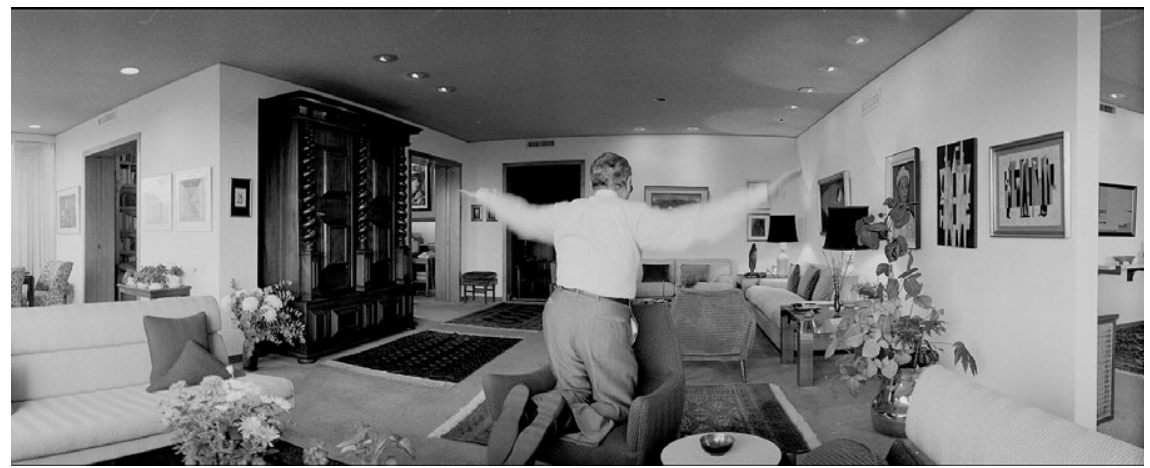

2. Pedro Meyer, Mi padre volando, 1987, Ciudad de México, negativo en b/n, 35mm, psfamipsssfF-Fdir856-ooi. (C) Archivo Pedro Meyer.

gonista. Mientras en la primera resalta el contraste entre el ocio representado como un trampantojo en el que se insertan en primer plano las figuras de dos oficinistas, en la segunda, aparentemente menos retocada, pero con modificación digital como hemos señalado, Meyer sitúa a los personajes sobre un telón de fondo que encuentra y fotografía en la parte posterior de un camión de carga. En las dos imágenes las palabras del fotógrafo cobran sentido: "siento que soy el director de un teatro: delante de mí hay un escenario, y voy a llamar en diferentes actos y establecer diferentes elementos en el escenario".55

Por otra parte, también encontramos disparos con cámara digital que remiten al trabajo desarrollado por Cartier-Bresson en el que prima la yuxtaposición de contrastes. Es el caso de Símbolos (2004) (fig. 3), ${ }^{56}$ donde sobre una misma pared en la que se observa un cartel de una dirigente de Calcuta se superponen varios emblemas, una esvástica y varias banderolas con la hoz y el martillo - de las que de manera circunstancial una de ellas tapa en parte el rostro de la dirigente. Paradójicamente, dos años después, en 2006, Meyer captará la imagen de Martin Luther King impresa en un abanico. La fotografía de idéntico nombre registra el instante en que una señora se protege del sol con este utensilio propagandístico en Los Ángeles. También en 2006, en La cabeza de san Juan Bautista y las papas fritas ${ }^{57}$ se aprecia un acto en el que el contraste es evi-

55. Meyer, Verdades y ficciones, in6.

56. Se trata de un original digital que puede consultarse en Meyer, Herejías, I79.

57. Se trata de un original digital. Meyer, Herejias, 239. 


\section{DOI: https://doi.org/10.22201/iie.18703062e.2021.119.2754}

64 NEKANE PAREJO Y AGUSTÍN GÓMEZ GÓMEZ

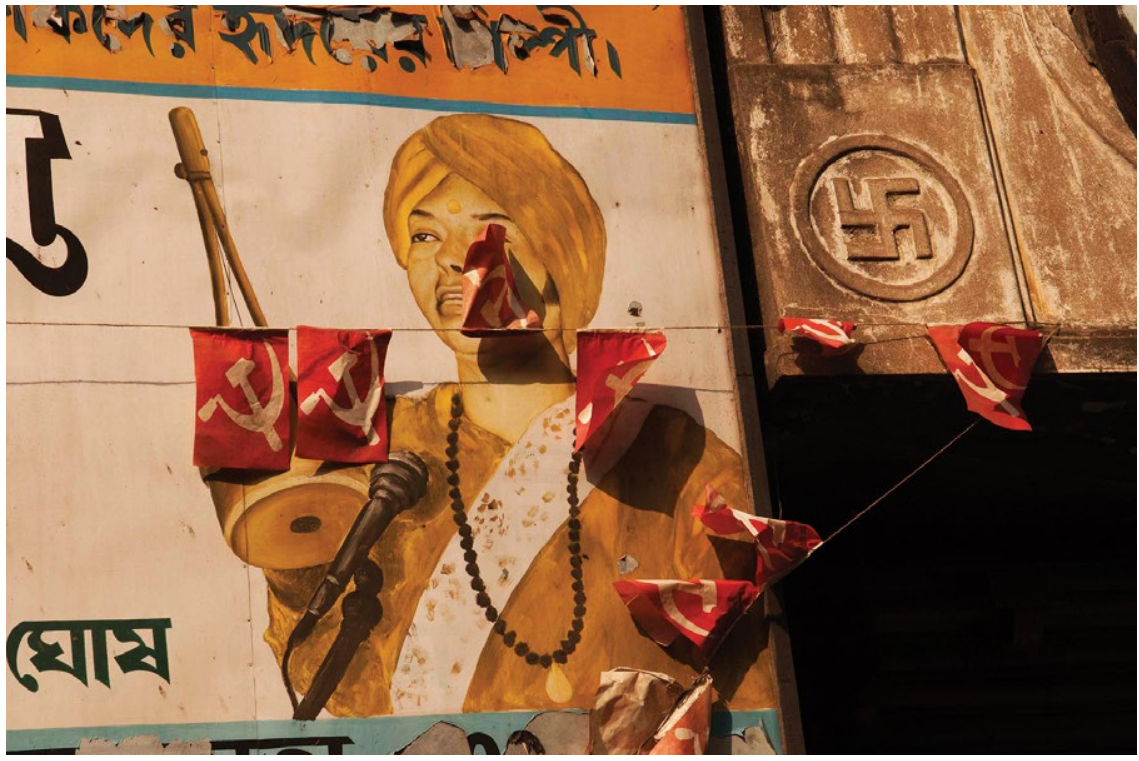

3. Pedro Meyer, Simbolos, 2004, Calcuta, India, InINDIIN0404-FDoI633-OoI. (C) Archivo Pedro Meyer.

dente. Mientras en primer plano un soldado con rictus serio porta la bandeja de san Juan Bautista con su cabeza, el que se sitúa inmediatamente detrás de él a la derecha da cuenta de un paquete de patatas fritas. Mediante el cotejo de estos dos gestos se establece un juego sobre la desacralización de las escenificaciones religiosas.

En este punto, y como transición al siguiente, subrayamos dos tomas con el mismo título: La caida (autorretrato)..$^{5}$ Ambas son originales digitales, aunque la primera como ha sido modificada responde a dos fechas, 2002 cuando se efectuaron los disparos fotográficos en Los Ángeles y 2008, momento en el que se produjeron las manipulaciones digitales a partir de la sesión anterior. Esta sesión se tradujo en un mosaico de seis tomas en el que se aprecian distintos momentos del cuerpo fragmentado y radiografiado de Meyer, así como una séptima en la que su rostro aparece bocabajo (en obvia correspondencia con su estado físico). De acuerdo con Vesta Mónica Herrerías Cuevas este acto fotográfico: "construye un tipo particular de autorretrato que convierte en memoria lo sufri-

58. Estas imágenes pueden consultarse en Meyer, Herejías, I58-I59. 
do, un acto que registra y congela las heridas". ${ }^{99}$ A partir de ahí, en 2008 construye una imagen en la que se conforma el recuerdo de lo que pudo ser su caída.

\section{El instante decisivo creado digitalmente}

En este subtítulo se pueden englobar tres posibilidades. A la primera nos hemos acercado con tomas como la de la caída de Meyer. Se trata de fotografías que cuentan con retoques que configuran encuadres de algo que estuvo a punto de suceder. En estos casos el autor considera las escasas diferencias, en cuanto a resultados finales se refiere, entre las posibles manipulaciones en la fotografía analógica y la digital. Después de todo, e independientemente de la tecnología empleada, para Meyer los fotógrafos son: "contadores de cuentos, pero eso no lo saben, creen que somos disparadores de instantes". ${ }^{60}$

A partir de esta afirmación emerge todo un posicionamiento acerca de cómo la fotografía analógica nos ha engañado a lo largo de su historia. En efecto, no podemos olvidar que un acercamiento a la fotografía documental tradicional evidencia que el "registro puro" no siempre estuvo exento de cierta planificación. Podemos referirnos a la planificación como señala Enrique Soto, en relación con los instantes decisivos, que "en cierta parte se buscan, en cierta forma los crea el ojo y la mente del fotógrafo que persigue y prefigura los acontecimientos" ${ }^{61}$ Pero, además, en ocasiones para lograrlos el autor no duda en emplear otras estrategias. Desde sus inicios los fotógrafos echaron mano tanto de manipulaciones antes, durante y después del acto fotográfico. Ya fueran éstas reconstrucciones, interpretaciones, manejos técnicos a priori o retoques después de la toma, el universo de la fotografía documental está plagado de ejemplos en este sentido. ${ }^{62}$

La única diferencia entonces radica en los medios empleados, e independientemente de que se pretenda mostrar imágenes sin manipular o alteradas "lo

59. Vesta Mónica Herrerías Cuevas, "Los autorretratos de Pedro Meyer”, https://studylib.es/ doc/4463329/los-autorretratos-de-pedro-meyer (consultado el 8 de octubre de 2019).

6o. Jorge Salgado, "Somos contadores de cuentos", https://library.co/document/rz337dmzpedro-meyer-un-poeta-de-la-luz.html (consultado el 25 de marzo de 2019).

6I. Soto, "Pedro Meyer", 54.

62. Parejo elabora las clasificaciones mencionadas y ejemplifica cada una de ellas. Para ampliar la información véase: Parejo, "De la fotografía documental al documento digital", I79196. 


\section{DOI: https://doi.org/10.22201/iie.18703062e.2021.119.2754}

que hemos dado en llamar fotografía tradicional puede ser producida ya sea de manera analógica utilizando procesos químicos, o digital en formato electrónico" ${ }^{63}$ Esta consideración implica que una fotografía analógica manipulada y una fotografía modificada de manera digital puedan reproducir un instante decisivo. Ahora bien, la segunda con una mayor comodidad.

Dentro de esta categoría de creaciones digitales, en la que uno de sus rasgos definitorios es que la manipulación es indetectable, es preciso destacar, entre otras, Los Meyer (1940/2000), ${ }^{64}$ donde encontramos una aparente toma familiar de dos padres con dos niños. En realidad, se trata de una composición en la que el fotógrafo aparece en dos ocasiones, a la derecha como hijo y a la izquierda como padre. No obstante, si ahondamos en el hecho de mostrar un momento decisivo no detectable y que ha sido creado digitalmente, debemos detenernos en ¿Donde está la lana? (1985/1999) (fig. 4). ${ }^{65}$ Aquí la copia final muestra a una señora degollando una oveja mientras en primer plano aparece un hombre con sendos billetes en cada mano. Meyer explica pormenorizadamente el acto fotográfico mediante las diversas tomas que obtuvo ese día. Las tiras de contactos evidencian que ambos personajes confluyen en el mismo escenario, pero no en el mismo encuadre. Para él "en el enfoque tradicional el haber arreglado previamente la composición no hubiera representado ningún problema". ${ }^{66} \mathrm{Y}$ expone algunas posibilidades: "Podría haberle pedido al hombre que se volteara y se colocara en el mismo lugar de la imagen final. O podría haber cambiado mi posición. En cualquier caso, tales prácticas nunca han sido mal vistas o consideradas como manipulación" ${ }^{67}$ Por tanto, esta imagen es una muestra de cómo es posible conseguir un instante decisivo con un programa informático, sin depender del azar y lo que es más importante para este fotógrafo, sin cambiar el significado de lo que estaba ocurriendo.

63. Pedro Meyer, "Traditional Photography vs. Digital Photography", http://www.zonezero. com/editorial/marzooI/march.html (consultado el in de abril de 2008).

64. Para obtener la imagen final se parte de un negativo en formato 6 × 6 y una imagen digital que han sufrido modificaciones digitales. Puede consultarse en Meyer, Herejías, 52.

65. Para obtener la imagen final se parte de negativos de $35 \mathrm{~mm}$ que fueron modificados digitalmente. Meyer, Herejías, 319.

66. Pedro Meyer, "Si te gustaba el trabajo documental, te encantarán las imágenes digitales", http://www.zonezero.com/magazine/articles/meyer3/o2sp.html (consultado el I4 de marzo de 20I8).

67. Pedro Meyer, "Si te gustaba el trabajo documental". 


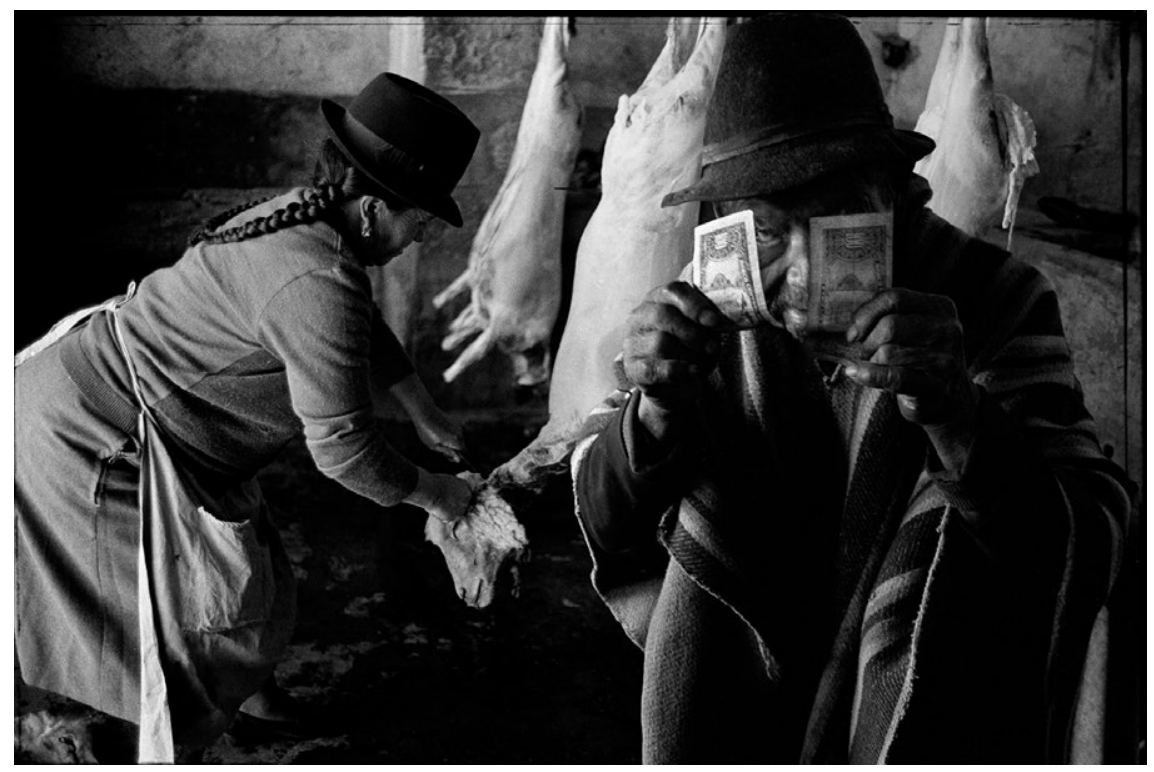

4. Pedro Meyer, ¿Dónde está la lana?, 1985/1999, Ecuador. (C) Archivo Pedro Meyer.

Sin embargo, en ocasiones (y ésta es la segunda posibilidad que Meyer emplea para crear el instante decisivo), aunque la manipulación digital no es obvia, y la información que proporciona la toma parece verosímil, a la par que irónica, los elementos que aparecen en la imagen nunca coincidieron en el espacio (como ocurría en el caso anterior). Por tanto, lo que se muestra en la toma no sucedió, es el fotógrafo quien coliga imágenes que observa en una misma porción de tiempo. Trabajadores migratorios mexicanos (1986/1990) (fig. 5$)^{68}$ es fruto de esta paradoja. En ésta también se parte de dos negativos de 35 milímetros que fueron yuxtapuestos de manera digital para crear un momento decisivo en el que concurren una veintena de trabajadores agrícolas mexicanos bajo una valla publicitaria que promociona servicios de lujo gratis desde un hotel. Servicios a los que evidentemente no tendrán acceso los trabajadores retratados que en realidad no se encontraban junto al anuncio, sino que como indica Meyer: "Vi a los trabajadores a unos kilómetros del anuncio. Yo había hecho la asociación entre las dos escenas en mi mente, pero estaban sepa-

68. Para obtener la imagen final se parte de negativos de $35 \mathrm{~mm}$ que fueron modificados digitalmente. Véase Meyer, Herejías, 64. 


\section{DOI: https://doi.org/10.22201/iie.18703062e.2021.119.2754}

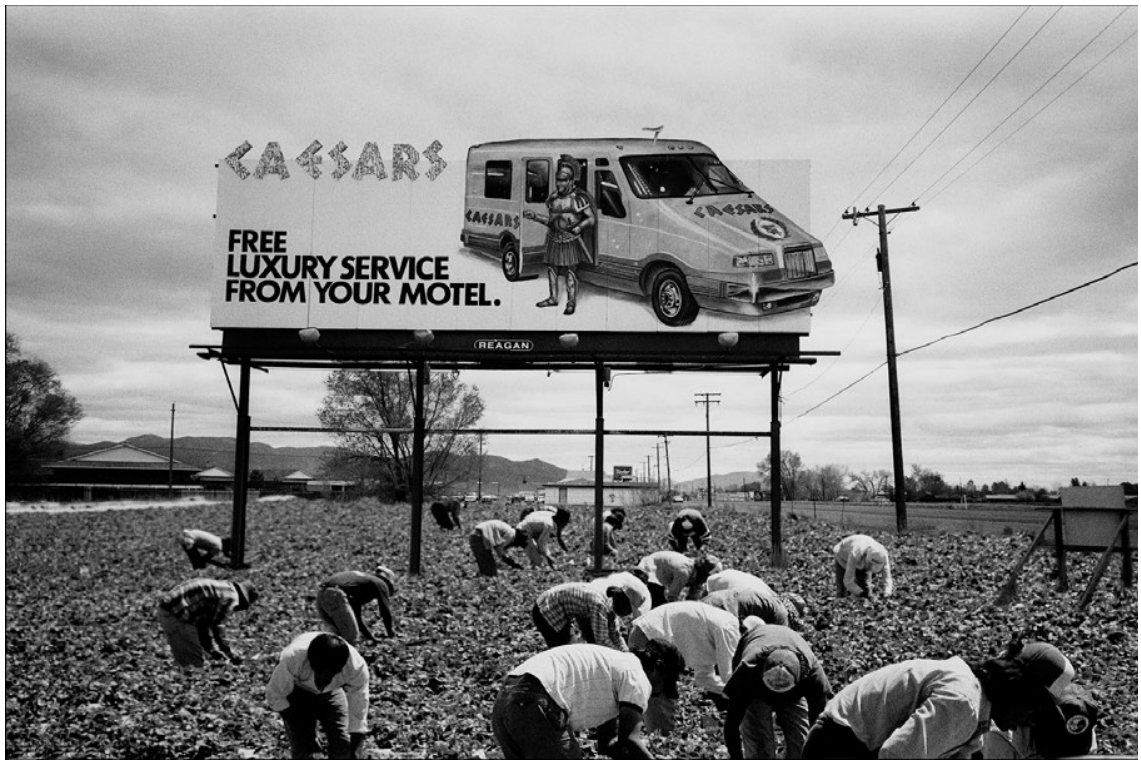

5. Pedro Meyer, Trabajadores migratorios mexicanos, 1986/1990, California, Estados Unidos, usarizusssfF-FDooooi-oo. (C) Archivo Pedro Meyer.

radas en el espacio." ${ }^{69}$ Por tanto, el fotógrafo en esa ocasión vincula dos actos fotográficos diferentes que se desarrollan en distintos escenarios y un tiempo asincrónico, pero cuyo nexo de unión son sus pensamientos. Y desde ahí, en diferido construirá esta imagen, ya que como él mismo manifiesta: "No tenía la intención de esperar una semana, diez días, o el tiempo necesario para que algo sucediera, para conseguir un 'momento decisivo' [...] Ese 'momento decisivo' sencillamente no ocurrió, había que crearlo."70

A partir de ahí entroncamos una tercera posibilidad que es aquella en la que Meyer recuerda haber visto una imagen susceptible de ser captada, pero en ese momento no tuvo la oportunidad de materializarla (a diferencia de la anterior donde las dos tomas, aunque en espacios diferentes, se realizan el mismo día). Desde este planteamiento, el hecho de hacerlo a posteriori en la computadora

69. John Mraz, “¿Qué tiene la fotografía de documental? Del fotoperiodismo dirigido al digital. Digitalizar al fotoperiodismo”, http://vi.zonezero.com/magazine/articles/mraz/ mrazo6sp.html (consultado el Io de marzo de 2018).

70. Meyer, Verdades y ficciones, in6. 
le parece un argumento de suficiente peso. Es el caso de La Plantación, el Centro, California, $1987 / 1995 .{ }^{71} \mathrm{La}$ toma final parte de un negativo realizado en California en 1987, al que ocho años más tarde se le añade el individuo que aparece de espaldas en primer plano. En definitiva, la persona de la copia final procede de la memoria del fotógrafo, ya que no la registró en el encuadre inicial. En cierto modo estamos ante la traslación de Fotografío para recordar a Recuerdo para fotografiar. En este sentido, Meyer expresa que: "Cuando creo una imagen o altero alguna parte, en realidad estoy restituyendo elementos que tal vez le faltaban, que eran imposibles de captar en su momento [...] Ahora, gracias a la fotografía digital, a las fotografías les puedo añadir mi propia memoria." ${ }^{72} \mathrm{Y}$ de este modo, apelando a la memoria, parece insertarse una oveja negra (recuérdese el borreguito negro de su primera toma a los I2 ańos) en la fotografía Insólita nevada en el Ajusco con oveja negra, 1966/2008. ${ }^{73}$ Encontramos ahí un negativo de un paisaje en blanco y negro de 1966 al que 42 años después se le añade una imagen digital de una oveja negra (que el fotógrafo no captó, pero permanecía en sus recuerdos).

\section{La imagen discordante: la ficción digital detectable}

En esta categoría se incluyen aquellas fotografías que han sido manipuladas y en las que la distancia entre el acto fotográfico y la copia final es obvia. Las alteraciones pueden ser diversas en estas fotografías en las que Meyer combina negativos, desenfoca algunas partes, borra otras, las pinta, las tapa con terceras, etc. En cualquier caso, son imágenes con numerosas capas intermedias que se alejan de su referente y en cierta medida violentan nuestro concepto de objetividad fotográfica. Aquellas para las que "la verdad constituye una opción, ya no una obstinación". ${ }^{74}$

7I. Esta fotografía y sus características puede consultarse en la página web del Museum of Contemporary Photography Columbia College Chicago, https://www.mocp.org/detail.php?$\mathrm{t}=$ objects\&type $=$ browse $\& \mathrm{f}=$ maker $\& s=$ Meyer $\% 2 \mathrm{C}+$ Pedro\&record $=\mathrm{O}$

72. Pedro Meyer, "Ensayos sobre Fotografío para recordar", http://v2.zonezero.com/index. php?option=com_content $\&$ view=article $\&$ id $=I 355$ : ensayos-sobre-fotografia-para-recordar \&catid=5:articles\&lang=es\&Itemid=o (consultado el 3 de octubre de 20I9).

73. Para obtener la imagen final se parte de un negativo en formato $6 \times 6$ y una imagen digital que han sufrido modificaciones digitales. Puede consultarse en Meyer, Herejias, I9.

74. Joan Fontcuberta, La furia de las imágenes. Notas sobre la postfotografía (Barcelona: Ga- 


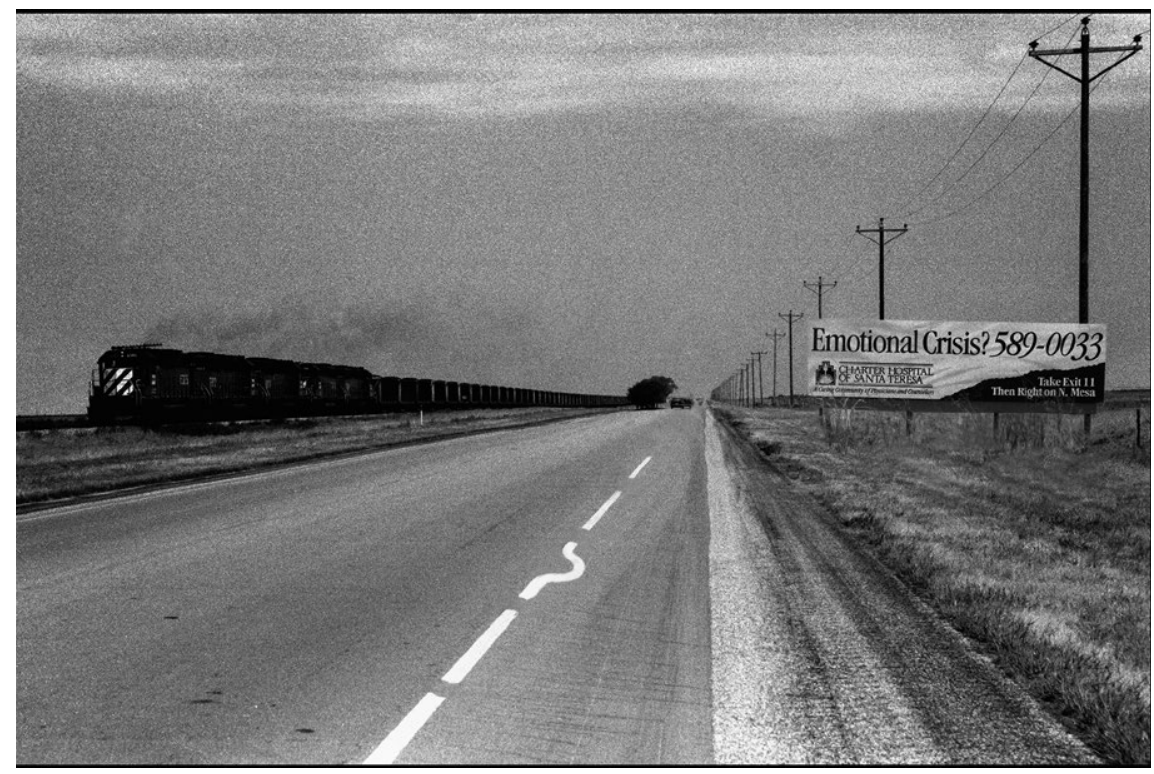

6. Pedro Meyer, Crisis emocional, 1990/1993, Texas, Estados Unidos, UsteXausssfFFDoooo2-004. (C) Archivo Pedro Meyer.

En ocasiones, como en Crisis emocional, 1990/1993 (fig. 6), ${ }^{75}$ se trata de pequeñas modificaciones que a partir de un concepto - el hecho de toparse con una valla publicitaria de una empresa cuyo cometido es ayudar a superar una crisis emocional—, se desencadena la necesidad de construir una imagen con mensaje. Ahí sólo se incluyen dos negativos, un paisaje con un tren y el de la valla, que se yuxtaponen en aras de la simetría y de otorgar un significado último acerca de la soledad. Después, añade un toque de humor cuando deforma la línea discontinua de una carretera. Precisamente esta fusión del humor, la metáfora y la crítica social es uno de los rasgos recurrentes de este autor. En este sentido, el director de coediciones internacionales de Lunwerg, Javier Ortega

laxia Gutenberg, 2016), 30.

75. Para obtener la imagen final se parte de un negativo de $35 \mathrm{~mm}$ que ha sido modificado digitalmente. Puede consultarse en Meyer, Herejías, 40. 


\section{DOI: https://doi.org/10.22201/iie.18703062e.2021.119.2754}

EL IMPACTO DE LAS NUEVAS TECNOLOGÍAS

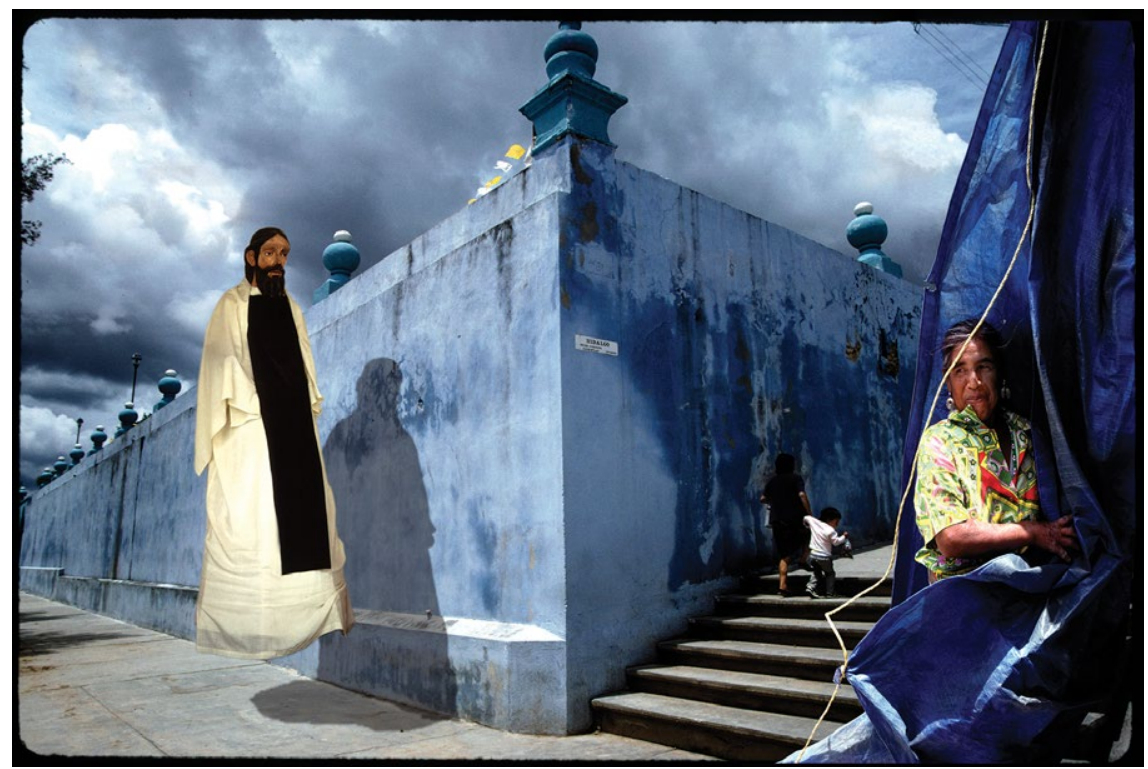

7. Pedro Meyer, El santo de paseo, 199i/1992, Nochixtlán, Oaxaca, México, MxмixtmxssfFFDoo030-002. (C) Archivo Pedro Meyer.

señala que "detrás de sus imágenes hay un finísimo sentido del saber sonreír para después, mirar, atrapar y archivar". ${ }^{76}$

En otras de tema religioso, como El santo de paseo, I991/1992 (fig. 7) ${ }^{77}$ o La tentación del ángel 1991/1992, ${ }^{78}$ las manipulaciones se vuelven más complejas y evidentes. De acuerdo con Green: "consolidan la experiencia americana en términos distintivamente religiosos y evangélicos. Unen y yuxtaponen momentos visuales discordantes que son fusionados en la memoria para construir apariciones de lo sagrado dentro de lo secular". ${ }^{79}$ En la primera, cuyo origen son tres transparencias a color de 35 milímetros, la composición remite a las prác-

76. Citado en Fran Casillas, "Las mentiras verdaderas de Pedro Meyer conquistan el planeta fotográfico", https://www.elmundo.es/elmundo/2008/10/24/cultura/I224858715.html (consultado el 5 de septiembre de 2020).

77. Para obtener esta imagen se modificaron digitalmente tres transparencias de $35 \mathrm{~mm}$, 106 .

78. Para obtener esta imagen se modificron digitalmente dos transparencias de $35 \mathrm{~mm}, \mathrm{I} 77$.

79. Jonathan Green, "La teoría de la relatividad según Pedro Meyer. Verdades y ficciones", https://n9.cl/on7jx (consultado el i9 de marzo de 20I8). 


\section{DOI: https://doi.org/10.22201/iie.18703062e.2021.119.2754}

ticas de las vanguardias históricas. En ella concurren diversos escenarios en sobreimpresión, cuyos originales son un paisaje urbano con una mujer y un nińo que suben unas escaleras, una mujer envuelta en un lienzo (fotografiada en casa de un amigo de Meyer) y un santo retratado en el patio de una iglesia. El hecho de que los dos últimos se inserten en el primer escenario sin una aparente lógica (la mujer a gran tamańo y en primer plano y el santo levitando) torna a la imagen inverosímil. Pero, para Meyer, esta fotografía resume los logros de la fotografía digital: "con la fotografía digital, uno puede hacer imágenes, que son representaciones de sueños, donde la imaginación puede fluir, o levitar, al igual que el santo". ${ }^{80}$

En La tentación del ángel se combinan dos transparencias, una que funciona como principal sobre la que se superpone la figura de una mujer. Mientras en la primera se percibe a unas personas disfrazadas entre las que destaca una niña en primer plano vestida de ángel, la segunda, según Meyer, se corresponde con una imagen que captó cuando una mujer le estaba enseñando cómo preparar un baño tradicional mexicano. En cualquier caso, ambos perfectamente verosímiles. Es su conjunción la que convierte a la percepción de la imagen como algo discordante. Esto se debe a que el fotógrafo ha focalizado la atención en el ángel (desenfocando al resto de las figuras) que mira distraídamente hacia la izquierda a la par que ha reducido y situado a la señora encima de la mesa de ajedrez delante del ángel. De este modo, la situación que se le presenta al espectador es una pequeña señora que camina sobre una mesa de ajedrez con una rama ardiendo y que se dirige hacia una nińa disfrazada de ángel del todo ajena a la situación.

Precisamente estas dos fotografías, que cuentan con un escenario común como es Oxaca y un imaginario pictórico evidente, son paradigmas significativos de esta categoría. Como expresa Green:

Aquí no hay una constante unificadora, no hay fijeza, no hay una coherencia absoluta. Lo que permanece constante es la realidad fotográfica de las partes componentes, pero la verosimilitud del todo es abandonada, y con ese abandono también renunciamos a la verdad fotográfica tradicional y entramos a un universo en donde la barrera entre realidad y mito se hace más permeable y transparente. ${ }^{81}$

80. Meyer, Verdades y ficciones, II7.

8I. Green, "La teoría de la relatividad según Pedro Meyer. Verdades y ficciones". 
Pero tampoco hay una constante unificadora en tomas de la era analógica cuyos retoques son también detectables, como Autorretrato en el infierno ${ }^{82}$ (1978/1978) donde se aprecia una clara manipulación en el proceso de revelado sobre una toma Polaroid. Si nos referimos a esta toma en este apartado es para corroborar la hipótesis de que el paso de la tecnología analógica a la digital no ha sido un impedimento, sino todo lo contrario, para que Meyer mantenga una línea fotográfica, independientemente del tipo de manipulaciones que pudieran haberse operado en la imagen.

\section{Conclusiones}

Partimos en este texto de una publicación anterior en la que confrontábamos la obra de Meyer con la de Henri Cartier-Bresson en función del término "instante decisivo" acuñado por este último. Transcurridos I2 ańos se advierte que el momento decisivo es un lugar común que cobra presencia durante toda su trayectoria, tanto la analógica como la digital.

Iniciamos este artículo con la afirmación de que la carrera de Meyer evidencia una obra en proceso en la que se distinguen a priori dos etapas, una analógica y otra digital. Pero el recorrido de este autor va más allá, ya que consolida tres fórmulas diferentes. En sus inicios sus tomas se caracterizan por la transparencia narrativa y la búsqueda del instante en el que se aúnan el humor, la metáfora y la crítica social. A partir de ahí la tecnología digital bifurcará su propuesta en dos posibilidades. Por un lado, aquella que usa los nuevos medios, pero que mantiene la apariencia de la foto documental. Es decir, la que se obtiene con un solo disparo de cámaras fotográficas digitales, o también en las que se combinan imágenes digitales con negativos analógicos que se tratan mediante la computadora. La importancia ahí radica en la apariencia del "haber estado alli" "83 al que aludió Roland Barthes. Por este motivo en un principio hemos categorizado los momentos decisivos que provienen de disparos fotográficos no manipulados, ya fueran analógicos o digitales, para posteriormente diferenciarlos de los momentos decisivos creados mediante la computadora, aunque algunos estén más próximos a su memoria que lo instan-

82. Para obtener la imagen final se parte de una fotografía Polaroid 3.5 x 4.2 modificada durante el revelado. Véase Meyer, Herejías, 55 .

83. Roland Barthes, La cámara lúcida (Barcelona: Paidós Ibérica, I980), I2I. 
táneo. Fotografías estas últimas en las que, a pesar de que conjugan escenarios y tiempos diversos, no se muestra sutura alguna y que podemos aceptar como momentos auténticos. Por otro lado, encontramos aquellas (en su mayoría elaboradas con tecnología digital, aunque también se localizan algunas con retoque analógico) en las que Meyer rompe con este pacto para configurar una realidad nueva y artificial. Pero una realidad en la que también están presentes los pilares que destacábamos como recurrentes: el humor, la metáfora y la crítica. Estos elementos, que configuran la estética de sus imágenes y que pudieran haber sido descubiertos con su obra digital ya estaban presentes desde sus inicios. Es más, estos rasgos que propiciaban en numerosas ocasiones la obtención del instante decisivo se mantienen en la obra de Meyer, aunque ahora el fotógrafo los trabaja en playback. \$ 